\title{
ULTRAVIOLET INDUCED LIGHT ERUPTIONS AND ABNORMAL LABORATORY THYROID TEST REPORTS- IS THERE ANY CORRELATION
}

\author{
Parikshit Sharma1, Akhil Shah ${ }^{2}$
}

${ }_{1}^{1}$ Associate Professor, Department of Dermatology, Index Medical College.

${ }^{2}$ Assistant Professor, Department of Dermatology, Index Medical College.

\section{ABSTRACT}

\section{BACKGROUND}

Ultraviolet induced light eruptions (PLE) is the commonest disease due to photosensitivity prevalent globally. Clinically, it was observed that many patients presenting with PLE were either already diagnosed with some thyroid function abnormality or later during the course developed some derangement in Thyroid Function Tests (TFT).

The aim of this study is to study the association between Light eruptions and Thyroid Stimulating Hormone values.

\section{MATERIALS AND METHODS}

It was a prospective observational study comprising of 90 subjects. Patients presenting to Dermatological Outpatient Department (OPD) of Index Medical College, Indore, diagnosed as having Polymorphic Light Eruptions were included in the study. After taking informed consent, their TSH levels were analysed and the observations were systematically noted to see how frequently they coexisted.

\section{RESULTS}

Thyroid Stimulating Hormone level (TSH) was abnormal in 30\% cases of patients with polymorphic light eruptions, out of which TSH was increased in 24.44\% ( $\mathrm{n}=22)$ individuals and decreased in 5.55\% $(\mathrm{n}=5)$ cases.

\section{CONCLUSION}

Our study highlights the need to routinely assess thyroid function tests in all patients of PLE, so that an early detection of subclinical hypothyroidism be made. We suggest larger population based studies and detailed thyroid profile evaluation be performed to establish a causal association between the two if any.

\section{KEYWORDS}

Photodermatosis, Light Eruptions, TSH.

HOW TO CITE THIS ARTICLE: Sharma P, Shah A. Ultraviolet induced light eruptions and abnormal laboratory thyroid test reportsis there any correlation. J. Evolution Med. Dent. Sci. 2017;6(12):960-962, DOI: $10.14260 / J e m d s / 2017 / 205$

\section{BACKGROUND \\ Ultraviolet induced light eruptions, more commonly Polymorphic Light Eruptions (PLE) is a common disease of photosensitivity. These are usually of recurring nature and manifests due to an abnormal reaction to sunlight (importantly the ultraviolet spectrum of sunlight). The lesions resolve without scarring1,2 and any other secondary skin changes. Its association with various dermatological and non-dermatological conditions like Lupus Erythematosus, 3 Actinic Prurigo, ${ }^{4}$ Photosensitive Psoriasis, ${ }^{5}$ Hepatitis $C$ virus infections, etc., has been reported. Few reports have also described association of PLE with thyroid function test abnormalities, but as both these conditions are commonly prevalent so it has not been confirmed beyond doubt. $6,7,8$}

Financial or Other, Competing Interest: None.

Submission 22-11-2016, Peer Review 06-12-2016,

Acceptance 08-12-2016, Published 09-02-2017.

Corresponding Author:

Dr. Parikshit Sharma,

\#11, Goyal Vihar Avenue,

Near Ganesh Temple,

Khajrana, Indore-452016.

E-mail: drparikshitsharma@gmail.com

DOI: $10.14260 /$ jemds $/ 2017 / 205$
It was observed frequently that lot of patients who presented to the outpatient department with PLE were either already under treatment for thyroid disorders or later developed thyroid function test abnormalities leading to a doubt whether the two entities are related or not. Literature available for the same was also limited, so there was a need to find if any significant association between the two exists or not.

Hence, in this study we planned to find out if any corelation exists between PLE and TSH values. The patients who presented to the Skin and VD outpatient department of our facility after being diagnosed as having PLE (Clinically) were advised Thyroid Stimulating Hormone (TSH) test. After evaluating the report, the co-existence of the two was assessed. This study may help us in determining the need to evaluate patients with PLE for thyroid function test abnormalities as a standard procedure, so that subclinical thyroid abnormalities may not be overlooked and they can be timely referred to the physicians for prompt management.

\section{MATERIALS AND METHODS \\ Sample Size}

90 patients diagnosed clinically as having PLE.

\section{Inclusion Criteria}

Patients of either sex and any age presenting with Polymorphic Light Eruptions at the Dermatology Outpatient 
Department of Index Medical College Hospital and Research Centre, Indore were included into the study.

\section{Exclusion Criteria}

Following patients were excluded from the study -

- Pregnant females.

- Patients with any inflammatory photodermatosis.

- Diagnosed cases of autoimmune connective tissue disorders (DLE, SLE, Scleroderma, etc.) and porphyrias.

- Use of systemic or topical steroid or any drugs causing photosensitivity such as quinolones, tetracyclines, sulfonamides, antimalarials and phenothiazines in last 3 months.

- Patients not giving valid consent for blood test.

\section{Methodology}

Patients of either sex presenting to Skin and V.D. Outpatient Department of Index Medical College, Indore, from January 2013 to October 2013 were included and after detailed history and necessary clinical examination the diagnosis of PLE was to be established.

After obtaining an informed consent, patients of PLE were subjected to laboratory tests of Thyroid Stimulating Hormone (TSH) and values were duly noted looking for any abnormality.

RESULTS

\begin{tabular}{|c|c|c|}
\hline Hormones & Levels & PLE Group n (\%) \\
\hline \multirow{2}{*}{ TSH } & Increased & $22(24.44)$ \\
\cline { 2 - 3 } & Decreased & $05(5.55)$ \\
\hline \multicolumn{2}{|c|}{$\begin{array}{c}\text { Table 1. Altered Thyroid Stimulating Hormone } \\
\text { in Polymorphic Light Eruption Patients }\end{array}$} \\
\hline
\end{tabular}

Table 1 shows number of cases with altered TSH levels among patients within PLE. TSH level was increased in $24.44 \%(n=22)$ of PLE cases, whereas it was decreased in $5.55 \%(n=5)$ of PLE cases.

\begin{tabular}{|c|c|}
\hline $\begin{array}{c}\text { Overall Thyroid Function } \\
\text { Abnormalities }\end{array}$ & $\begin{array}{c}\text { PLE Patients } \\
\text { n (\%) }\end{array}$ \\
\hline Yes & $27(30.00)$ \\
\hline No & $63(70.00)$ \\
\hline Total & $90(100.00)$ \\
\hline
\end{tabular}

Table 2. Overall Thyroid Stimulating Hormone

Abnormality in Polymorphic Light Eruption Patients

Table 2 shows overall prevalence of thyroid stimulating hormone abnormalities in PLE patients. The prevalence of overall thyroid function abnormalities in subjects was 30\% (n $=27$ ). Overall thyroid function abnormalities were not detected in $70 \%(n=63)$ subjects in PLE patients.

\section{DISCUSSION}

In our study (Table 1) Thyroid Stimulating Hormone (TSH) abnormalities were found in $30 \%(n=27)$ cases of PLE. These findings were consistent with earlier study by Lata Sharma et al, $^{6}$ where abnormal Thyroid Function Test was seen in $25 \%$ in study group and $7 \%$ in control group. Similarly, in another study by Seetharam et $\mathrm{al}^{7}$ where they sought association of PLE with autoimmune thyroiditis, 25.9\% cases reported with abnormal Thyroid Function Test (hypothyroidism only). In our study, Thyroid Stimulating
Hormone was found to be increased in $24.44 \%(n=22)$ of PLE patients and was decreased in $5.55 \%(n=5)$ cases.

Overall thyroid stimulating hormone test abnormalities (Table 2) were found in 30\% of PLE patients. As discussed before the overall thyroid function test abnormalities were similar to previous reports, in which Researchers observed significant association with PLE. Among these are reports by Hasan et $\mathrm{al}^{8}{ }^{\text {Seetharam et }} \mathrm{al}^{7}$ and Lata et $\mathrm{al}^{6}$ where they found high prevalence of thyroid function test abnormalities in patients/individuals with PLE.

\section{Limitations of Study}

Sample size of 90 patients of PLE is small as both these conditions pf PLE and thyroid function abnormalities are common in prevalence by themselves independently.

\section{CONCLUSION}

Thyroid Stimulating Hormone (TSH) test levels were frequently found deranged in our patients (in 30\% of the cases) with polymorphic light eruptions, which is among the commonest disease of photosensitivity around the world. Among all the conditions, we observed striking association of PLE with increased thyroid stimulating hormone values (24.44\%).

As it was clinically observed that many patients with PLE were either on treatment for thyroid disorders or developed them later, our study helps in further validating this association

We suggest the need of more elaborate studies with large sample size involving larger population at different centres, so that a definite causal relationship between PLE and thyroid function abnormalities can be established.

If causal association is further validated it will help physicians and dermatologists to manage cases of both PLE and thyroid disorders in a better and prompt way, thereby making evaluation of patients coming in outpatient department with PLE for thyroid function abnormalities as a standard procedure, so that no subclinical cases be missed and properly followed up.

\section{REFERENCES}

[1] Clayton R, George S. Haemorrhagic polymorphic light eruption: two cases of a rare variant. Photodermatol Photoimmunol Photomed 2006;22(3):166-7.

[2] Commens C. Polymorphic light eruption sine eruptione and brachioradial pruritus. $\mathrm{Br} J$ Dermatol 1988;119(4):554.

[3] Millard TP, Lewis CM, Khamashta MA, et al. Familial clustering of polymorphic light eruption in relatives of patients with lupus erythematosus: evidence of a shared pathogenesis. Br J Dermatol 2001;144(2):334-8.

[4] Grabczynska SA, McGregor JM, Kondeatis E, et al. Actinic prurigo and polymorphic light eruption: common pathogenesis and the importance of HLA-DR4/DRB1*0407. Br J Dermatol 1999;140(2):2326.

[5] Ros AM, Eklund G. Photosensitive psoriasis. An epidemiologic study. J Am Acad Dermatol 1987;17(5 Pt 1):752-8. 
[6] Lata S, Sachin L, Singh SK. Thyroid function tests in cases of polymorphic light eruption: a case-control study. Indian Dermatology Online Journal 2014;5(3):291-5.

[7] Seetharam KA, Sridevi K. Association of polymorphic light eruption and autoimmune thyroiditis 2010;76(6)704-5.
[8] Hasan T, Ranki A, Jansen CT, et al. Disease associations in polymorphous light eruption. A long-term follow-up study of 94 patients. Arch Dermatol 1998;134(9):10815. 